\title{
USING EFFECT CATALOGUES FOR THE DESIGN OF SENSING MACHINE ELEMENTS - METHOD AND EXEMPLARY APPLICATION
}

\author{
Harder, André; \\ Gross, Hans Joachim; \\ Vorwerk-Handing, Gunnar; \\ Kirchner, Eckhard \\ Technical University Darmstadt
}

\begin{abstract}
Close to process measuring improves the data quality of a condition monitoring process. A possibility to access such measurements comes with the addition of a sensory function in machine elements. For a systematic development of sensing machine elements, an approach is presented for the identification of possible measurands to determine a variable of interest. Based on a modelling of physical causeeffect-relationships by using an effect matrix and an effect catalogue it allows to consider both direct and indirect measurements for the determination of measurands in technical systems.

The presented approach is initially applied to develop a sensory solution for self-lubricated fibrecomposite sliding bearings. The aim is to measure a variable of interest that can give a conclusion about the estimated remaining useful lifetime. The development process is described and possible solutions for measurement concepts are presented. The electrical capacity measurement, evaluated as the most promising concept, is described in detail and experimental results are presented.

These results show the applicability of the sensory concept and therefore, the benefits of the presented approach.
\end{abstract}

Keywords: Design methods, Sensory Machine Elements, Conceptual design, Industry 4.0

\section{Contact:}

Harder, André

Technical University Darmstadt

Institute of Product Development and Machine Elements

Germany

harder@pmd.tu-darmstadt.de 


\section{INTRODUCTION}

The maintenance of technical plants and machines is crucial for their availability and reliability. If wear is not detected in a reasonable time, downtimes and consequently losses of availability have to be accepted. One way of reducing these downtimes is to carry out predictive maintenance of technical plants and machinery at regular intervals. Blechschmidt and Marz (2018) show that the same maintenance intervals are used as a basis for similar machines, which leads to the replacement of components before their theoretically possible end of lifetime. In addition, planned maintenance intervals also result in losses of availability of the technical systems and machines.

To enable predictive maintenance that is oriented to the actual condition of the components, sensing machine elements (SME) are of increasing relevance. With them, it is for example possible to monitor the current state of wear and to plan maintenance measures accordingly. On the one hand, this avoids unplanned system downtimes or short-term maintenance work, and on the other hand, it prevents the replacement of components based on purely running time and not on the actual state of wear. Another advantage and a major potential of sensing machine elements according to Martin et al. (2018) and Vorwerk-Handing et al. (2019) is their standardisation, which enables easy integration into new as well as existing technical systems. In addition, sensing machine elements provide in-situ data, which also enables in-process monitoring of the overall system. The sensing rolling bearing developed by Schirra et al. (2018), the sensing hydrodynamic plain bearing by Harder and Kirchner (2019), or the sensing timing belt by Grosskurth and Martin (2019) are current examples of the increased development of sensing machine elements.

The current approach to the development of sensing machine elements is mainly based on experience about metrologically usable relationships. A central and recurring question in the development of sensing machine elements is, which variables are potentially measurable and best suited to obtain the required information. In this context, the so far used experience-based "best practice" approaches show two main weaknesses: On the one hand, developer-related experience in the field of sensory usable relationships is assumed and, on the other hand, there is at least an unconscious pre-fixation on conventional or established solutions. This pre-fixation can further constitute an obstacle in the development of new (innovative) solutions.

In order to overcome a lack of experience and/or pre-fixations, a methodically supported solutionneutral discussion of potential measurement variables comes to the fore (Fleischer et al. (2018)). The relationship between a variable of interest and potentially measured variables is generally established via physical effects. At this point, the approach developed by Vorwerk-Handing (2021) uses an analogy to the realisation of functions in product development. A physical catalogue system is used to systematically establish potentially usable relationships between a variable of interest to be determined and potential measured variables.

In this paper, the application of the developed approach is considered in the context of the development of a sensory plain bearing. In this way, first conclusions on the applicability and usefulness of the approach are drawn in an initial validation.

\section{METHODICAL APPROACH}

Starting from the variable of interest in a technical system, connections to potential measurands have to be established systematically, because both direct and indirect measurements have to be considered for the determination of physical quantities in technical systems. For this purpose, the approach proposed by Vorwerk-Handing (2021) is applied, which is based on a modelling of physical causeeffect relationships by using an effect matrix and an effect catalogue. First the approach proposed by Vorwerk-Handing (2021) is described.

A desired variable of interest can be measured, if it is the cause of a change in a measureable variable (effect). Figure 1 shows this relationship with the example of a spring force meter, where the force is the variable of interest and the measured variable is the displacement. To get information on the variable of interest, the model of evaluation has to describe the connection between cause and effect. In the case of the spring force meter the stiffness of the spring connects cause and effect. A measured variable can only be suited for a measurement, if this connection exists within the considered system. Since a sensor changes a measurement signal, a measurement can also be seen as recording the effect of a cause on the sensor. The aim of the methodical approach is to conclude the cause from the effect (cf. Figure 1). 


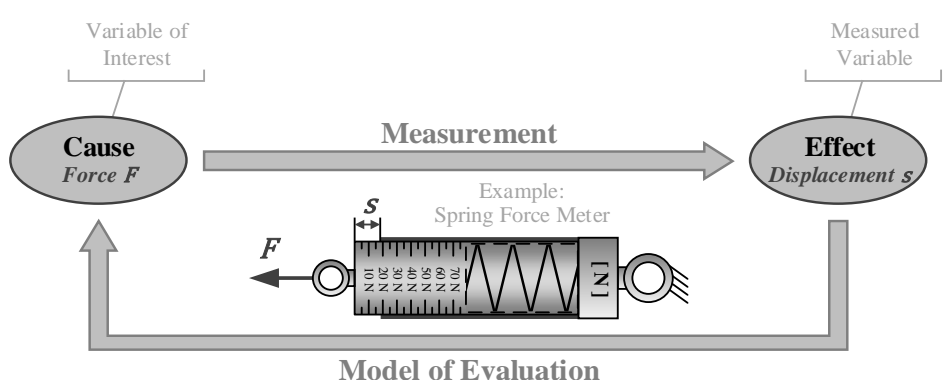

Figure 1. Cause-effect relationship in a mechanical sensor - Example spring force meter

Physical effect catalogues, e.g. according to Koller (1998) or Roth (2000) respectively, were developed to identify a physical effect or a chain of physical effects realising a given function within the considered system borders. According to Vorwerk-Handing (2021), these are in principle suitable for establishing a connection between a variable of interest and potential measured variables, but have two main limitations if one aims to identify cause-effect relationships in form of effect chains. On one hand, both effect catalogues focus on an effect to be realised and not a cause. This is important since effect catalogues are in general not invertible and it is generally not possible to exchange cause and effect. For example, it is possible to determine the change of the temperature (cause) by measuring the expansion of a certain length (effect). However, it is generally not possible to measure the change of a certain length by measuring its temperature. On the other hand, the approaches do not consider design parameters of the technical system. Both limitations result from the original purpose of the catalogues. According to the product development process, cf. product model pyramid according to Ehrlenspiel and Meerkamm (2018) in Figure 2, physical effect catalogues were developed to improve the availability and the exploitation of existing knowledge about physical effects for the realisation of defined functions. In the intended context, a physical catalogue system is used to identify metrologically usable relationships between a variable of interest and potential measured variables based on an existing system. Accordingly, design information about the basic system is already available, which is consequently integrated into the approach.

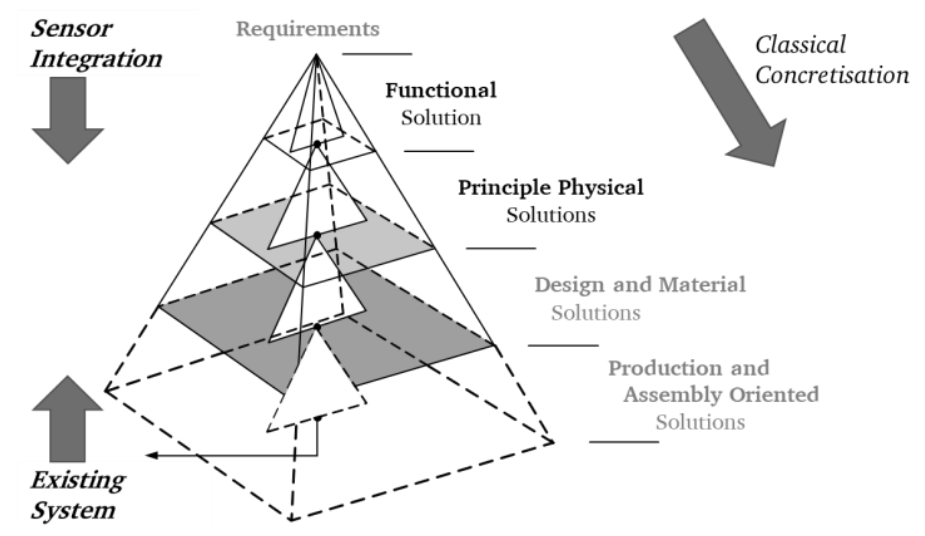

Figure 2. Product model pyramid according to Ehrlenspiel and Meerkamm (2017): Phases of the product development process along an increasing concretisation

Taking the identified restrictions as a starting point, Vorwerk-Handing developed a catalogue system with the aim to establish a system-dependent connection between a system-specific process or state variable and potential measurands by modelling physical effects. The developed catalogue system consists of a two-dimensional effect matrix and a one-dimensional effect catalogue (cf. Figure 3), comparable to the ones of Koller (1998) and Roth (2000) respectively. The effect matrix is used to establish a connection between a cause (variable of interest) and potential effects (measurands). This catalogue lists causes in columns and the resulting effects in rows. Effect numbers listed in the main section symbolise on the one hand the existence of a physical effect that describes the connection between the cause and the potentially resulting effect and on the other hand serves as an interface to the effect catalogue. The one-dimensional effect catalogue lists the relevant information and references about the physical relationships systematically in a table. For this purpose, information on the respective physical effect is presented in the main section in form of a sketch, the involved physical quantities, an example and references to additional literature. The aim of the access section is to enable 
the user to pre-select the potentially usable physical effects. In order to enable a comparison between requirements as well as boundary conditions of the individual effects and the individually considered technical system, effect-specific required properties of the technical system are listed (e.g., state of aggregation or type of movement as well as effect-specific properties).

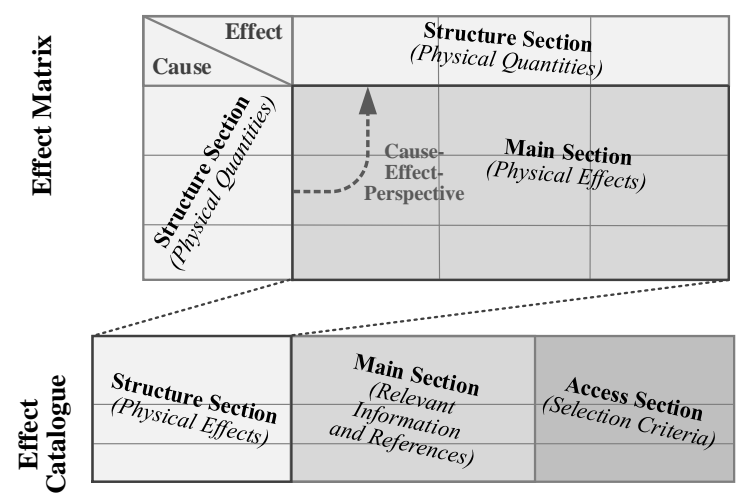

Figure 3. Overview of the basic structure and content of the effect matrix and effect catalogue

There are two basic degrees of freedom to identify a usable connection between the variable of interest and potential measured quantities:

- Starting from the initial location of the variable of interest, the other components within the scope of consideration can be considered as potential measurement locations.

- The number of considered changes of the physical quantity within a component can be varied.

Since the scope of consideration is deliberately limited to the sliding bearings in this paper, the first degree of freedom is omitted. The number of conversions included is determined by the number of iterations in the cause-and-effect analysis in the effect matrix (cf. Figure 4).

Due to the development stage of the catalogue system, the established catalogues according to Koller (1998) and Roth (2000) respectively were used for initial validation of the approach. The results achieved in this way can be used as an early indicator of the applicability and usefulness of the catalogue system developed by Vorwerk-Handing, since in terms of content, the catalogues used form the basis for the developed catalogue system. Therefore, they can in principle be used to identify cause-and-effect relationships.

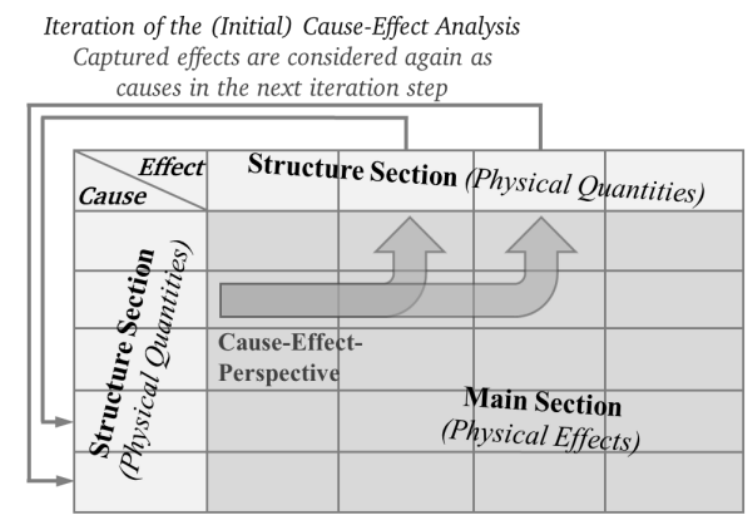

Figure 4. Procedure for an iteration of an (initial) cause-effect analysis

\section{APPLICATION OF THE APPROACH - DEVELOPMENT OF A MEASURING CONCEPT FOR SELF-LUBRICATING SLIDING BEARING}

For a first initial proof of the functionality, the presented approach was applied during an Industrial Corporation Project with the Federal Mogul Deva GmbH. Therefore, Mr. Gross had the task to evaluate possible sensoric solutions and to design a self-lubricated fibre-composite sliding bearing with sensory functionality as a part of his Bachelor thesis (Gross (2020)). Neither having previous experience with the development of sensing machine elements nor with the design or application of 
sliding bearings, he was able to apply the presented approach unbiased. Mr. Harder supervised the Bachelor thesis and Mr. Vorwerk-Handing supported the project methodically.

\subsection{Project Description}

Self-Lubricated Fibre-composite sliding bearings (cf. Figure 5) consist of two different layers. The inner sliding layer is made of Polytetrafluoroethylene (PTFE) fibres and an epoxy resin with added graphite. The outer carrying layer is made of glass fibres. The sliding layer is worn over the lifetime of the bearing due to its operating principle. The abraded material functions as a solid lubricant and reduces the friction between the shaft and the bearing. Steinhilper and Sauer (2018) or Niemann et al. (2019) give a more detailed description on the operating principle of self-lubricating sliding bearings.

The remaining useful lifetime (RUL) of the bearing is proportional to the minimal thickness of the sliding layer, and when this layer is worn out, the bearing has to be exchanged. Due to typical applications as in construction machinery, lock gates or port cranes, the exchange of a bearing can be time-consuming and cost-expensive. Furthermore, the bearing positions are often badly accessible and a condition monitoring from outside is difficult to accomplish.

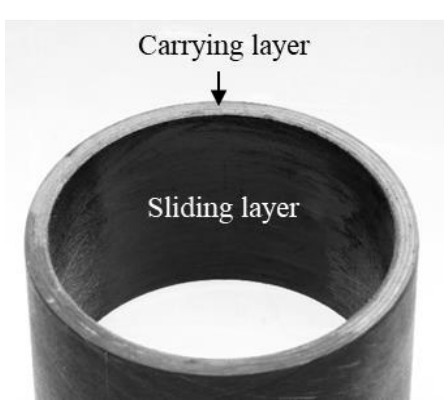

Figure 5. Self-lubricated fibre-composite sliding bearing deva.tex 552.

(The Image is used with the permission of Federal Mogul Deva GmbH)

Thus, there is a demand for a sliding journal bearing with sensory functionality, which is able to obtain the information that is necessary for the estimation of the remaining useful lifetime of the bearing. The following requirements are derived with the project partner and are requisite for a sensory sliding bearing:

- The sensory sliding bearing has to provide information, which can be converted in its remaining useful lifetime.

- For retrofitting reasons, the dimensions of the bearing must not be altered. Sensor carrying or sensor integrated systems must be implemented inside the bearing (installation space neutrality).

- Additional manufacturing steps due to the integration of the sensory system shall be minimized. An integration of the additional steps into the current manufacturing process is preferred (assembly effort and costs).

- $\quad$ The sensory principle must not endanger the user safety (security).

- The resolution and sensitivity of the measuring principle shall be sufficient for the desired application.

- The useful lifetime of the sensory components must be higher than the one of the bearing.

Based on the requirements, measuring concepts for a sensory sliding bearing system are developed with the application of the effect catalogue approach.

\subsection{Evaluation of applicable sensory principles}

For the systematic investigation of measurable physical effects, the variable of interest and the system boundary have to be defined, before the effect catalogues can be used in accordance with Section 2. In the considered system, the respective border is drawn around the shaft and the sliding bearing. For the sliding bearing the variable of interest is the minimal sliding layer height $h_{\mathrm{SL}, \mathrm{min}}$, because of its direct correlation with the RUL. This geometric quantity is used as cause in the effect catalogue.

For a derivation of the physical effects for the detection of the abrasion, the functional parameter matrices of Roth (2000) will be used in a first iteration with the minimal sliding layer height $h_{\mathrm{SL} \text {,min }}$ as variable of interest. In the effect catalogue of Roth, all geometric displacement quantities are summarized as the geometric quantity $s$. The geometric displacement is chosen as the cause for gaining measurable physical parameters (effects). In Figure 6, the first iteration for the geometric displacement quantity $s$ as the cause is shown according to the procedure depicted in Figure 4. Physical connections between cause 
and effect can only be found in the grey cells of the matrix. According to the variable of interest $s$, row 2 is further considered. It shows ten possible cause effect connections, for the measurement of the minimal sliding layer height $h_{\mathrm{SL} \text {,min }}$ suitable connections are marked with an "x". Connections marked with an "o" do exist, but cannot be used for the measurement in a sliding bearing, e.g. column 13 shows the connection between a geometric displacement $s$ and the hydrostatic pressure $p_{\mathrm{d}}$. In principle, it is possible to measure the hydrostatic pressure in a contained liquid to determine its depth. However, since the sliding bearing operates without a liquid, this connection cannot be used in this application.

\begin{tabular}{|c|c|c|c|c|c|c|c|c|c|c|c|c|c|c|c|c|c|}
\hline \multicolumn{2}{|c|}{ Effect } & $F$ & $s$ & $p_{\mathrm{i}}$ & $v$ & $M$ & $\phi$ & $L$ & $\omega$ & $u$ & $\pi$ & $V$ & $p_{\mathrm{d}}$ & $I$ & $\phi$ & $Q$ & $U$ \\
\hline Cause & No. & 1 & 2 & 3 & 4 & 5 & 6 & 7 & 8 & 9 & 10 & 11 & 12 & 13 & 14 & 15 & 16 \\
\hline$F$ & 1 & & & & & & & & & & & & & & & & \\
\hline$s$ & 2 & $\mathrm{x}$ & $\mathrm{o}$ & & $\mathrm{o}$ & $\mathrm{o}$ & $\mathrm{o}$ & & $\mathrm{o}$ & & & & $\mathrm{o}$ & $\mathrm{o}$ & & $\mathrm{x}$ & $\mathrm{x}$ \\
\hline$p_{\mathrm{i}}$ & 3 & & & & & & & & & & & & & & & & \\
\hline$\ldots$ & $\ldots$ & & & & & & & & & & & & & & & & \\
\hline
\end{tabular}

Figure 6: First iteration in the transposed functional parameter matrix (section) according to Roth (2000).

After the first iteration physical effects for potential detection of the abrasion in the sliding bearing are given only between the force $F$, the electrical potential $Q$ or the electric voltage $U$. The effects, which are potentially suitable for measuring the variable of interest, are discussed and the respective results are shown in Figure 7. Between the force and the geometric shift, the effect of the shear deformation can be used for potential detection of the abrasion of the plain bearing. Due to the prevailing frictional forces in operation, corresponding shear and normal stresses are induced in the bearing. As the wear in the bearing progresses, it is assumed that the measurable stresses due to the change of the contact angle $\gamma_{\mathrm{c}}$ between the bearing and the shaft also changes. The principle of this concept is shown in Figure 7a.

Between the electrical potential and the geometric shift, the effect of the potential of a capacitor is given. Beside the effect of the induction voltage due to an electric field strength, also the effect of the capacitor with a force effect of the electric field on a particle between the capacitor plates, is given. Both of the physical effects are between the electric voltage and the geometric shift. With the effect of the induction voltage, the abrasion of the plain bearing can be detected by a current-carrying conductor which is represented by the shaft and its generated magnetic field strength around the shaft. With increasing abrasion, the distance between the shaft and a corresponding sensor decreases and the magnetic field strength increases. In Figure $7 \mathrm{~b}$ the principle of this measurement concept is shown. The problem with this solution is the high required voltage for measurable geometric shifts. Furthermore, the magnetic field strength has to be measured orthogonal to the shaft. The orthogonal integration of a suitable sensor results in high effort for the integration of the sensor in the sliding layer.

On the contrary, the effect of the capacitor can be used by inserting a metal foil or similar into the sliding bearing. In this case, the system consisting of the shaft and the sliding bearing can be modelled as a cylindrical capacitor with the sliding layer as the dielectric, as shown in Figure 7c. As a result of changes of the sliding layer height, the capacitance of the capacitor changes.

To check the completeness of the measurable physical effects for the detection of the eccentricity, the effect catalogue according to Koller (1998) is used, in addition to the detected effects from the functional parameter matrix shown in Figure 6. With the collection of the physical effects according to Koller, one additional effect is found. This effect is the resistance of an electric conductor which is based on its cross section and its length. From this effect results the concept idea of inserting a wire into the sliding layer of the bearing. The principle of this measurement concept is shown in Figure $7 \mathrm{~d}$. By measuring the electrical resistance of this wire, the wear condition in the sliding bearing is determined. With increasing wear, the wire is worn away and its measurable resistance decreases.
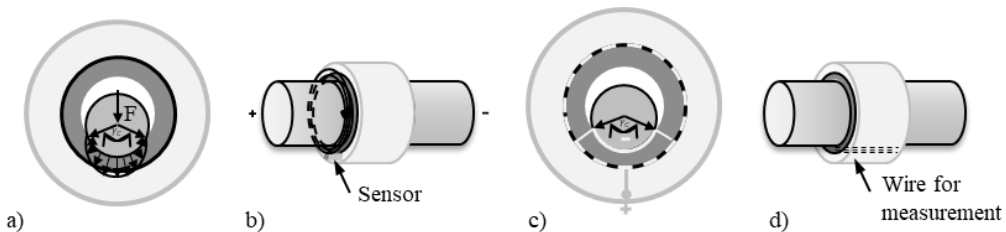

Figure 7. Overview of the different measurement concepts: a) shear and normal stresses measurement, b) inductive measurement, c) capacitive measurement, d) resistive measurement 
For further elaboration of the concepts, they are compared with each other by a weighted point evaluation. Here the evaluation factors assembly expenditure, resolution, sensitivity, installation space neutrality, costs, and security are relevant. With a pair comparison, the evaluation factors are weighted in each case and applied to the concepts afterwards. With this procedure, the concept of the sliding bearing modelled as a cylindrical capacitor is rated as the best concept, which will be investigated further and elaborated in the following section. Further information on the individual measurement concepts and their evaluation can be found in Gross (2020).

\subsection{Sensoric utilized sliding bearing solution}

The in the previous section chosen operating sensor principle is the bearing modelled as an electric capacitor. For shaping the bearing as a capacitor, a metal foil with the width $L$ is added in circumferential direction during the manufacturing process between the sliding layer and the carrying layer of the sliding bearing as shown in Figure 8a).

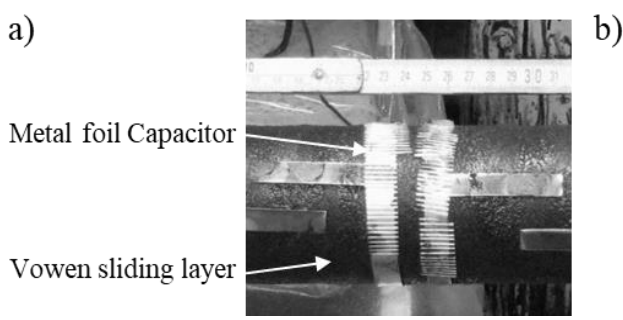

b)

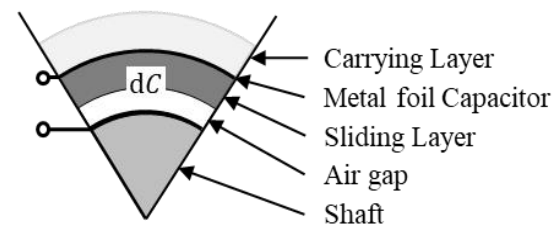

Figure 8:a) Added metal foils as cylindrical capacitors during the manufacturing process of the sensorial sliding bearing prototypes. (The Image is used with the permission of Federal Mogul Deva $\mathrm{GmbH}$ ) b) Infinitesimal element of the capacitor $C$.

Combined with the steel shaft, this arrangement can be described as an eccentric cylindrical capacitor. The sliding layer and the air inside the bearing are the dielectrics of two capacitors in series connection, as shown in Figure 7b). The resulting differential capacity of an infinitesimal element of the capacitor $C$ can be calculated as:

$$
\mathrm{d} C=\frac{\varepsilon_{0} \cdot \varepsilon_{\mathrm{A}} \cdot \varepsilon_{\mathrm{SL}} \cdot\left(\frac{D_{0}}{2}+h_{\mathrm{SL}, 0}\right) \cdot L}{\varepsilon_{\mathrm{A}} h_{\mathrm{SL}}(\theta)+\varepsilon_{\mathrm{SL}} h_{\mathrm{A}}(\theta)} \mathrm{d} \theta
$$

$\varepsilon_{\mathrm{A}}$ and $\varepsilon_{\mathrm{AL}}$ are the specific permittivity of the air and the sliding layer, $\theta$ is the attitude angle, $D_{0}$ is the nominal bearing diameter, $h_{\mathrm{SL}}(\theta)$ and $h_{\mathrm{A}}(\theta)$ are the local heights of the sliding layer and the air gap between the bearing and the shaft respective to the attitude angle. $h_{\mathrm{Sl}, 0}$ is the initial sliding layer height of the new bearing. $\varepsilon_{0}$ is the vacuum permittivity. The heights of the sliding layer and the air gap in the bearing change with increasing wear and dependent on the load conditions of the bearing. Since the load condition in the bearing depends on its application, both the point and circumferential load conditions are considered The calculation of the layer heights is based on the calculation of the film thickness in hydrodynamic journal bearings, presented in e.g. Prashad (2006).

For point load condition the layer heights are:

$$
\begin{aligned}
& h_{\mathrm{SL}, \mathrm{P}}(\theta)=\left\{\begin{array}{cl}
h_{\mathrm{S} 1,0}+\frac{s}{2}-\left(h_{\mathrm{S} 1,0}+\frac{s}{2}-h_{\mathrm{S} 1, \mathrm{~min}}\right) \cdot \cos (\theta) & \text { for }|\theta| \leq \theta_{\mathrm{SL}} \\
h_{\mathrm{S} 1,0} & \text { for }|\theta|>\theta_{\mathrm{SL}}
\end{array}\right. \\
& h_{\mathrm{A}, \mathrm{P}}(\theta)=\left\{\begin{array}{cl}
0 & \text { for }|\theta| \leq \theta_{\mathrm{SL}} \\
\frac{s}{2}-\left(h_{\mathrm{S} 1,0}+\frac{s}{2}-h_{\mathrm{S} 1, \mathrm{~min}}\right) \cdot \cos (\theta) & \text { for }|\theta|>\theta_{\mathrm{SL}}
\end{array}\right.
\end{aligned}
$$

$s$ is the initial bearing clearance, and $\theta_{\mathrm{SL}}$ is the attitude angle of the worn sliding layer area. It is calculated as:

$$
\theta_{\mathrm{SL}}=\cos ^{-1}\left(\frac{\frac{s}{2}}{h_{\mathrm{S} 1, \mathrm{O}}+\frac{s}{2}-h_{\mathrm{S} 1, \min }}\right)
$$


Figure 9 shows the layer height distribution of the layer height and the height of the air gap between the bearing and the shaft. In point load condition the shaft "digs" into the sliding layer in the direction of the radial load.

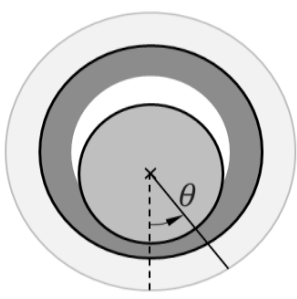

b)

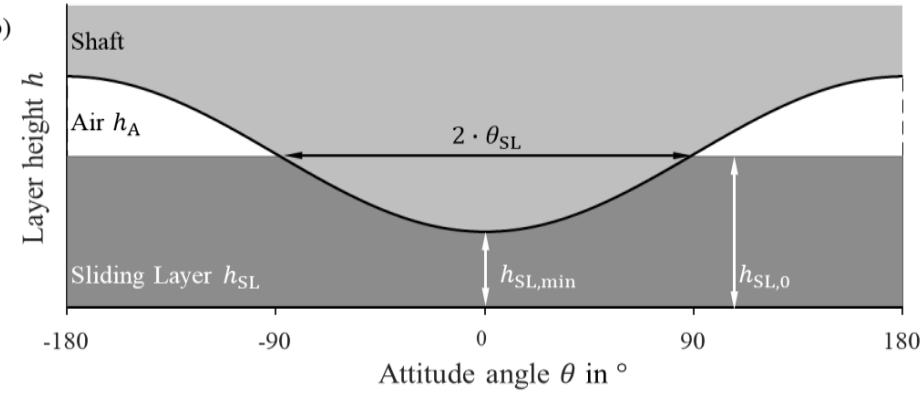

Figure 9: Sliding Bearing under point load condition. a) front view; b) Layer height distribution over the attitude angle.

For circumferential load conditions the layer heights are:

$$
\begin{aligned}
& h_{\mathrm{SL}, \mathrm{C}}(\theta)=h_{\mathrm{SL}, \min } \\
& h_{\mathrm{A}, \mathrm{C}}(\theta)=\left(h_{\mathrm{S} 1,0}+\frac{s}{2}-h_{\mathrm{S} 1, \min }\right) \cdot(1-\cos (\theta))
\end{aligned}
$$

Figure 10 shows the layer height distribution for circumferential load condition. In a circumferential load condition, the sliding layer is worn equally over the attitude angle. Depending on the load condition, Equation (2) and (3) or Equation (5) and (6) can be substituted in Equation (1) and integrated analytically similar to Prashad (2006) or numerically with, for example, MATLAB.
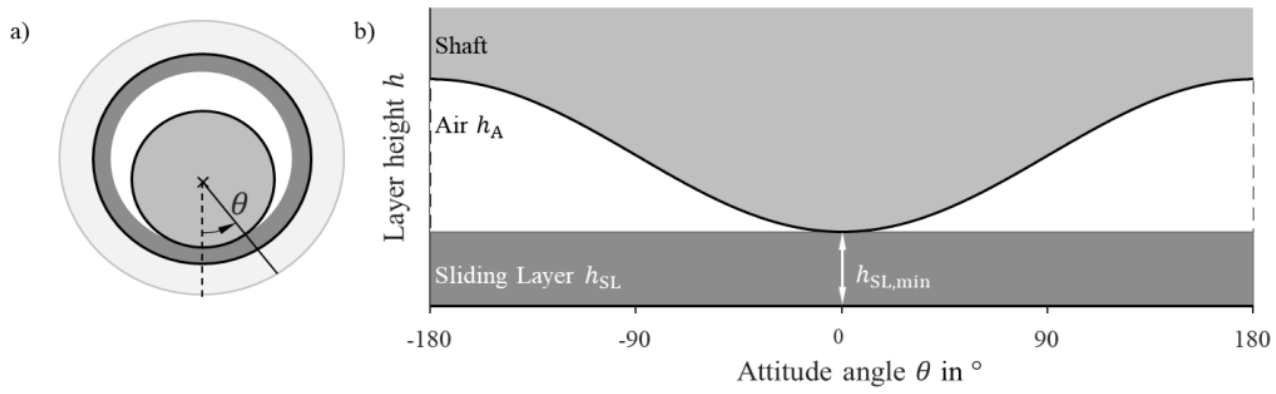

Figure 10: Sliding Bearing under circumferential load condition. a) front view; b) Layer height distribution over the attitude angle.

For the purpose of proving the functionality of the proposed concept, several prototypes of the sensorial sliding bearings were manufactured. The parameters of these prototypes are given in Table 1 . Because of scheduling reasons, the proof of concept was not done by applying wear on a testing rig, but by removing the material of the sliding layer on a lathe. This artificial wear is equivalent to the wear in a circumferential load condition. The measured capacity is shown in Figure 11. It is plotted over the remaining minimal sliding layer height. For comparison, the calculated capacity under point and circumferential load are also shown in Figure 11. It is observable that the measured data behave as expected similar to the calculated capacity of the circumferential load condition. The almost constant offset is caused by the housing, which carries the bearing and which functions as a parallel capacitor.

Table 1. Parameter of the manufactured prototype

\begin{tabular}{|l|c|r|}
\hline Nominal Bearing diameter & $D_{0}$ & $70 \mathrm{~mm}$ \\
\hline Bearing width & $B$ & $55 \mathrm{~mm}$ \\
\hline Capacitor foil width & $L$ & $10 \mathrm{~mm}$ \\
\hline Initial sliding layer height & $h_{\mathrm{SL}, 0}$ & $1 \mathrm{~mm}$ \\
\hline Initial bearing clearance & $S$ & $0.023 \mathrm{~mm}$ \\
\hline Specific permittivity air & $\varepsilon_{\mathrm{A}}$ & 1.0006 \\
\hline Specific permittivity sliding layer & $\varepsilon_{\mathrm{SL}}$ & 5.083 \\
\hline
\end{tabular}


The proof of concept shows, that the measured and calculated capacities are similar and sliding bearings can be utilized as sensing machine elements. On this basis, it is stated that the presented approach leads to useful results. Also it is possible to use the effect catalogue method to evaluate possible disturbances. Since Figure 6 shows possible cause-effect connections for the measurement, it also shows possible sources of disturbance. The variable of interest $h_{\mathrm{SL} \text {, min }}$ can, e.g., be altered by the bearing load, which can lead to an elastic deformation of the sliding layer. A change in temperature can also lead to a thermal expansion of the bearing and shaft and can therefore change the sliding layer height. The measured capacity $C$ can be disturbed by another material, which could fill the air gap in the bearing (e.g. water, dirt) and change the permittivity. Before an application in real systems the impact of these disturbances has to be inspected.

Furthermore it had to be considered, that neither the capacity curve under point load nor under circumferential load is strictly monotonically increasing. Therefore, the application of this concept as a condition monitoring system requires some sort of memory, which allows a clear connection of the measured capacity and the minimal sliding layer height of sliding bearings. A calibration of the sensing bearing in the surrounding housing is also necessary to reduce the measured offset. Furthermore, for a real utilisation in technical systems, additional functions have to be added, such as energy harvesting or data transfer.

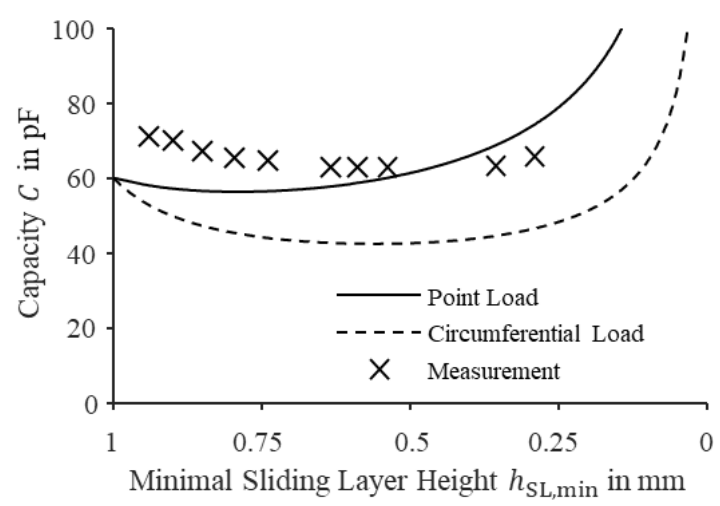

Figure 11: Measured capacity of the bearing prototype and calculated capacity under point and circumferential load.

\section{CONCLUSION}

This article shows how effect catalogues can support the systematic development of sensing machine elements by establishing potentially usable relationships between a variable of interest to be determined and potential measured variables. In an industrial corporation project, the approach of using a physical catalogue system developed by Vorwerk-Handing (2021) was applied to develop possible sensory concepts for self-lubricated sliding bearings. The most promising of these concepts - the measurement of the electric capacity through a metallic foil between the sliding and the carrying layer - was further developed and first experimental evaluations show a similarity between the calculated and the measured capacities. Differences in measuring are explained and possible disturbances of the measurement are discussed. Mr. Steffen Kropp, Senior Engineering Manager at Federal Modul Deva GmbH, evaluates the results of the industrial project as following:

"In the industrial cooperation project "Development of a measuring concept for self-lubricating sliding bearing" with the Technical University of Darmstadt, we were able to prove that fibre-composite plain bearings are indeed able to measure the current wear using a capacitive measuring principle. Under certain conditions, this plain bearing concept is able to determine the wear in the bearing without additional external sensors."

Though a full validation for the functionality of the presented approach has to be made, a first application in the Industrial project showed its advantages. The systematic procedure, with which possible measurands are found for the desired variable of interest, reduces the likelihood of missing a relevant measuring principle. In addition, the approach is applicable without previous experience about metrologically usable relationships or having an expertise with certain machine elements and supports therefore the development of unbiased solutions. Furthermore, the use of physical cause-effect-chains allows not only detecting possible measurands for a desired variable of interest, but also possible disturbances, that can influence both of them. With these advantages, the presented approach is useful in 
the methodical development of sensing machine elements and thereby increase the effectiveness of the predictive maintenance of technical systems.

In the next steps, the presented approach should be used to develop a software tool, which can support the applicant. The systematics of effect catalogues and the iterative procedure of the approach are suited for a software application. The possibility of identifying disturbances of the designed sensory system is initially shown and has to be further expanded. Finally, it is necessary to validate the functionality of the approach.

\section{ACKNOWLEDGMENTS}

The authors thank Federal Mogul Deva GmbH for the opportunity to apply the developed method in an Industrial Cooperation project and for providing of the product images.

\section{REFERENCES}

Blechschmidt, N. and Marz, M. (2018): „Produktivitätstreiber Maintenance 4.0: Instandhaltungsmanagement für die Fabrik der Zukunft”. Productivity Management, 2018.3, pp. 55-57.

Ehrlenspiel, K. and Meerkamm, H. (2017): Integrierte Produktentwicklung: Denkabläufe, Methodeneinsatz, Zusammenarbeit. Carl Hanser Verlag, Munich.

Fleischer, J.; Klee, B.; Spohrer, A.; Merz, S., Metten, B. (2018): Leitfaden Sensorik für Industrie 4.0 - Wege zu kostengünstigen Sensorsystemen. Verband Deutscher Maschinen- und Anlagenbau (VDMA) and Karlsruher Institute of Technology (KIT), Institut of Production Science (wbk), Frankfurt/Main.

Grosskurth, D. and Martin, G. (2019), "Intelligente Zahnriemen", 20. GMA/ITG-Fachtagung Sensoren und Messysteme 2019, Nuremburg, 25.-26.06.2019, pp. 738-743, DOI: 10.5162/sensoren2019/P2.14.

Gross, H. J. (2020), Entwicklung eines Messkonzeptes für selbstschmierende Gleitlagerbuchsen, Bachelor thesis, Technical University of Darmstadt, Institute for Product Development and Machine Elements.

Harder, A. and Kirchner, E. (2019), “Untersuchung sensorischer Eigenschaften von Gleitlagern”, Dresdner Maschinenelemente Kolloquium, Dresden, 26.-27.11.2019, Sierke Verlag, Goettingen, pp. 533-542.

Koller, R. (1998), Konstruktionslehre für den Maschinenbau: Grundlagen zur Neu- und Weiterentwicklung technischer Produkte mit Beispielen, Springer Verlag, Berlin.

Martin, G., Schork, S. Vogel, S. Kirchner, E. (2018), "MME - Potentiale durch mechtronische Maschinenelemente", Konstruktion, Vol. 70, pp. 71-75.

Niemann, G., Winter, H., Höhn, B. R., Stahl, K. (2019). Maschinenelemente 1: Konstruktion und Berechnung von Verbindungen, Lagern, Wellen. Springer, Berlin, Heidelberg. DOI: 10.1007/978-3-662-55482-1

Prashad, H. (2006), Tribology in electrical environments, Elsevier, Amsterdam.

Roth, K. (2000), Konstruieren mit Konstruktionskatalogen: Band 1: Konstruktionslehre, Springer, Berlin.

Schirra, T.; Martin, G.; Vogel, S. and Kirchner, E. (2018), "Ball bearings as sensors or systematical combination of load and failure monitoring", 15th International Design Conference, Dubrovnik, 21.-24.05.2018, The Design Society, Glasgow, pp. 3011-3022, DOI: 10.21278/idc.2018.0306.

Steinhilper, W., Sauer, B. (2018). Konstruktionselemente des Maschinenbaus 2: Grundlagen von Maschinenelementen für Antriebsaufgaben, Springer, Berlin Heidelberg. DOI: 10.1007/978-3-642-39503-1

Vorwerk-Handing, G., Gwosch, T., Schork, S., Kirchner, E., Matthiesen, S. (2019), "Classification and examples of next generation machine elements", Forschung im Ingenieurwesen 84 (1), pp. 21-32. DOI: 10.1007/s10010-019-00382-1.

Vorwerk-Handing, G. (2021), Erfassung systemspezifischer Zustandsgrößen - Physikalische Effektkataloge zur systematischen Identifikation potentieller Messgrößen, Dissertation, Technical University of Darmstadt, Institute for Product Development and Machine Elements. 